\title{
Adult Kasabach-Merritt Syndrome due to Hepatic Giant Hemangioma
}

\author{
Ahmet Aslan ${ }^{\mathrm{a}} \quad$ Andreas Meyer zu Vilsendorf ${ }^{\mathrm{b}}$ \\ Moritz Kleine $^{b}$ Martin Bredt ${ }^{c}$ Hüseyin Bektas ${ }^{b}$ \\ aDepartment of General Surgery, Faculty of Medicine, Mustafa Kemal University,

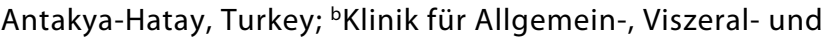 \\ Transplantationschirurgie and 'Abteilung für Pathologie, Medizinische \\ Hochschule Hannover, Hannover, Germany
}

\section{Key Words}

Kasabach-Merritt syndrome $\cdot$ Hemangioma $\cdot$ Liver

\begin{abstract}
Cavernous hemangiomas are the most common benign tumors of the liver. They can reach enormous sizes and cause various complications. Kasabach-Merritt syndrome is a rare but serious complication characterized by consumptive coagulopathy caused by the hemangioma; mortality rate ranges between 10 and $37 \%$. More than $80 \%$ of cases occur within the first year of life. Goals of the treatment are to control the coagulopathy and thrombocytopenia as well as to eradicate the hemangioma. Different nonsurgical treatment regimens are performed, including systemic corticosteroids, irradiation and various chemicals. Surgery should be limited to symptomatic or complicated cases. Although difficult, resection of the tumor is usually curative. Here we present a 44-year-old woman with giant hepatic hemangioma causing Kasabach-Merritt syndrome managed by enucleation.
\end{abstract}

\section{Introduction}

Cavernous hemangiomas are the most common benign tumors of the liver. Giant cavernous hemangiomas are those larger than $4 \mathrm{~cm}$ in diameter and can reach enormous sizes. The diagnosis should not be augmented by biopsy because of the risk of hemorrhage [1]. Enucleation is an underused procedure that if carefully performed allows resection of giant hemangiomas with reduced blood loss and preservation of virtually all normal hepatic parenchyma [2]. Kasabach-Merritt syndrome (KMS) is a consumptive coagulopathy caused by hemangioma. The mortality rate of this syndrome is $10-37 \%$ [3]. 
Here we present a 44-year-old woman with giant hepatic hemangioma causing KMS managed by enucleation.

\section{Case Report}

A 44-year-old female presented with pain persisting for two months on the right upper abdominal quadrant. An abdominal ultrasound performed one month earlier showed a mass in the liver. She had been examined by a gynecologist two years before due to dysmenorrhea and her clotting tests revealed that she had a prolonged clotting time but no cause was found. She did not use any medication including oral contraceptives. Physical examination was normal. Complete blood count showed that she had trombocytopenia (platelet count $20,000 / \mathrm{mm}^{3}$ ). The international normalized ratio was prolonged (table 1) and Quick test time was shortened. Abdominal ultrasound and contrast computerized tomography revealed two different masses on the liver. One of the masses was a $46 \times 27 \mathrm{~mm}$ hypovascular inhomogeneous mass with centrally cystic degeneration on segment 2 . The other mass was a $218 \times 158 \times 128 \mathrm{~mm}$ giant mass on the right lobe with the same characteristics (fig. 1 , fig. 2). Laparotomy revealed multiple numerous microhemangiomas on the remaining liver. The major hemangioma was totally enuclated ( $\underline{\text { fig. } 3}$ ), but the lesser one was located on the middle of the left lobe and could damage the remaining liver tissue and so was not suitable for excision. The major hemangioma weighed 2,800 g and measured $25 \times 19 \times 9 \mathrm{~cm}$. The postoperative course was uneventful. Platelet count was normal on postoperative day 3 . Pathology was consistent with cavernous hemangioma (fig. 4). The 6-month control visit was uneventful.

\section{Discussion}

Cavernous hemangiomas are the most frequent type of benign liver tumor mostly discovered unexpectedly, either when patients undergo routine examination for nonspecific abdominal complaints or during laparotomy [4]. KMS is a rare but serious complication defined by a huge hemangioma with thrombocytopenia and consumption coagulopathy due to endothelial defects within the hemangioma. More than $80 \%$ of cases occur within the first year of life [5]. The etiology and malignant transformation is unknown and the typical patient is an infant, often male [6]. Mostly they remain asymptomatic and are discovered incidentally. Rarely a large hemangioma may cause right upper quadrant pain, but the potential for rupture is negligible and does not in itself constitute an indication for resection [7, 8]. The hematologic features of KMS and those of chronic coagulopathy seen with other vascular malformations can be similar, which makes KMS difficult to distinguish [9].

In the diagnostic process, these lesions must first be distinguished from hepatic malignancies. The widespread use of ultrasound and computed tomography scanning has made the occasional finding of a 'nonhomogeneous area' more common. Magnetic resonance imaging and computed tomography reveal a vascular enhancing mass which is difficult to differentiate from a vascular malformation [6]. Magnetic resonance imaging has reported sensitivities and specificities of up to $100 \%$ by gadolinium administration and is the preferred imaging technique for lesions smaller than $15 \mathrm{~mm}$ [10].

Treatment of this syndrome is often difficult, but resection of the tumor is usually curative. Since they are benign lesions, treatment is not imperative. There are two major treatment objectives, the control of the coagulopathy and thrombocytopenia as well as eradication of the hemangioma. Different treatment regimens are performed, including systemic corticosteroids, irradiation, compression, embolization, antifibrinolytic agents, platelet aggregation inhibitors, interferon low dose heparin infusion, cryoprecipitate and aminocaproic acid [11-18]. Surgery should be limited to symptomatic or complicated cases. However, Velin et al. suggested that removal of localized hemangiomas in 
nonfunctional areas is the most appropriate treatment for the patients with KMS [19]. There have been reports of 'enucleation' of the tumor [20]. We treated the patient by excising only one hemangioma because there was not sufficient residual liver tissue. Instead we cauterized the mass and still we treated KMS. Extremely rarely, hemangiomas of the liver require liver transplantation. Meguro et al. [6] and Klompmaker et al. [21] described one case of successful liver transplantation in an adult with giant hemangiomas and KMS.

In conclusion, KMS is a complicated disease due to its mortality and difficult treatment modalities. Surgical treatment is still controversial but the only curative modality.

Table 1. Clotting tests of the patient

\begin{tabular}{lcccc}
\hline & $\begin{array}{l}\text { One week } \\
\text { before } \\
\text { surgery }\end{array}$ & $\begin{array}{l}\text { Preope- } \\
\text { rative }\end{array}$ & $\begin{array}{l}\text { Postope- } \\
\text { rative } \\
\text { day 7 }\end{array}$ & $\begin{array}{l}\text { Normal } \\
\text { range }\end{array}$ \\
\hline Trombosit & 190 & 87 & 251 & $150-450$ \\
Quick test & 88 & 49 & 109 & $70-130$ \\
INR & 1.07 & 1.53 & 0.95 & $0.90-1.25$ \\
APTT & 30 & 33 & 31 & $25.9-125.0$ \\
\hline
\end{tabular}



\begin{tabular}{l|l} 
Case Reports $h$ & $\begin{array}{l}\text { Case Rep Gastroenterol 2009;3:306-312 } \\
\text { D0l: 10.1159/000242420 }\end{array}$
\end{tabular}

Fig. 1. Axial CT image of the hemangioma.

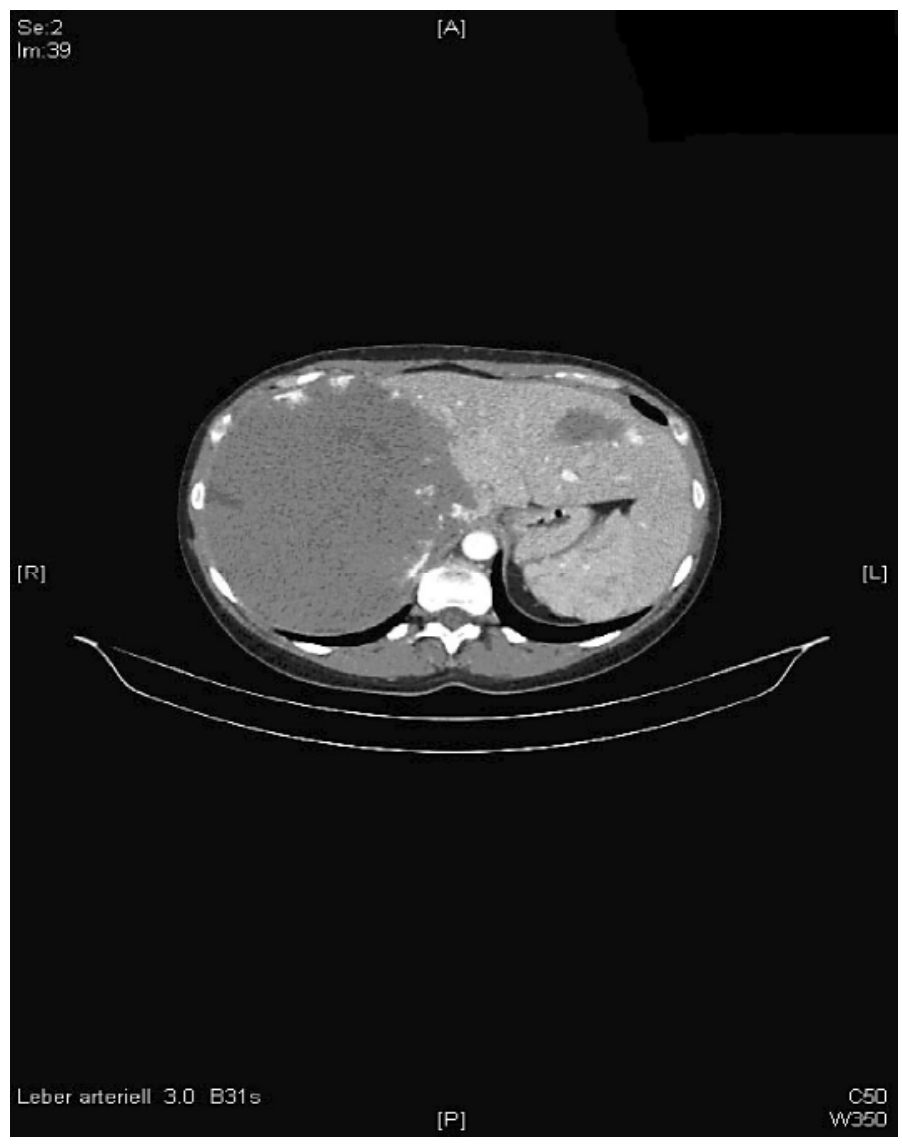



\begin{tabular}{l|l} 
Case Reports $h$ & $\begin{array}{l}\text { Case Rep Gastroenterol 2009;3:306-312 } \\
\text { D0l: 10.1159/000242420 }\end{array}$
\end{tabular}

Fig. 2. Coronal CT image of the hemangioma.

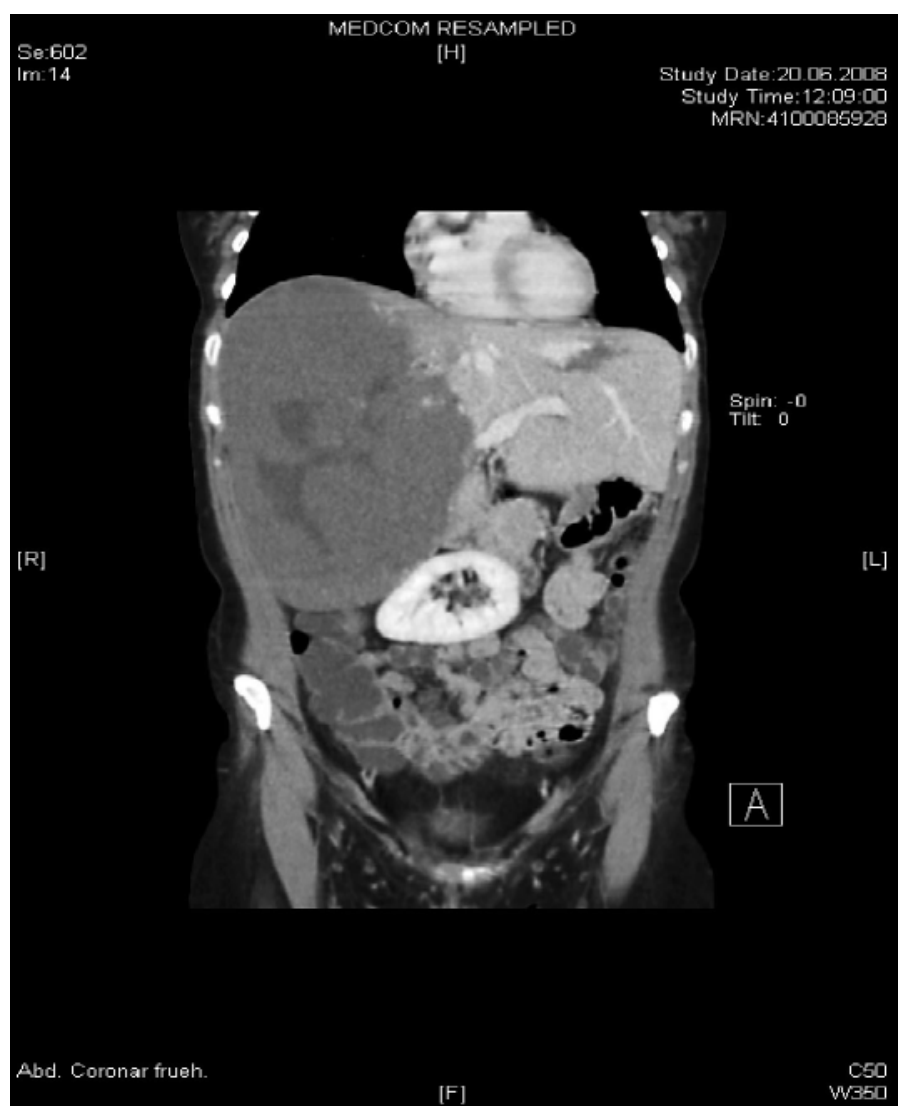




\begin{tabular}{r|l|l|l} 
Case Reports in & $\begin{array}{l}\text { Case Rep Gastroenterol 2009;3:306-312 } \\
\text { D0I: 10.1159/000242420 }\end{array}$ & Published online: November 20, 2009 & $\begin{array}{l}\text { O 2009 S. Karger AG, Basel } \\
\text { ISSN 1662-0631 } \\
\text { www.karger.com/crg }\end{array}$ \\
\hline
\end{tabular}

Fig. 3. Surgically removed hemangioma.

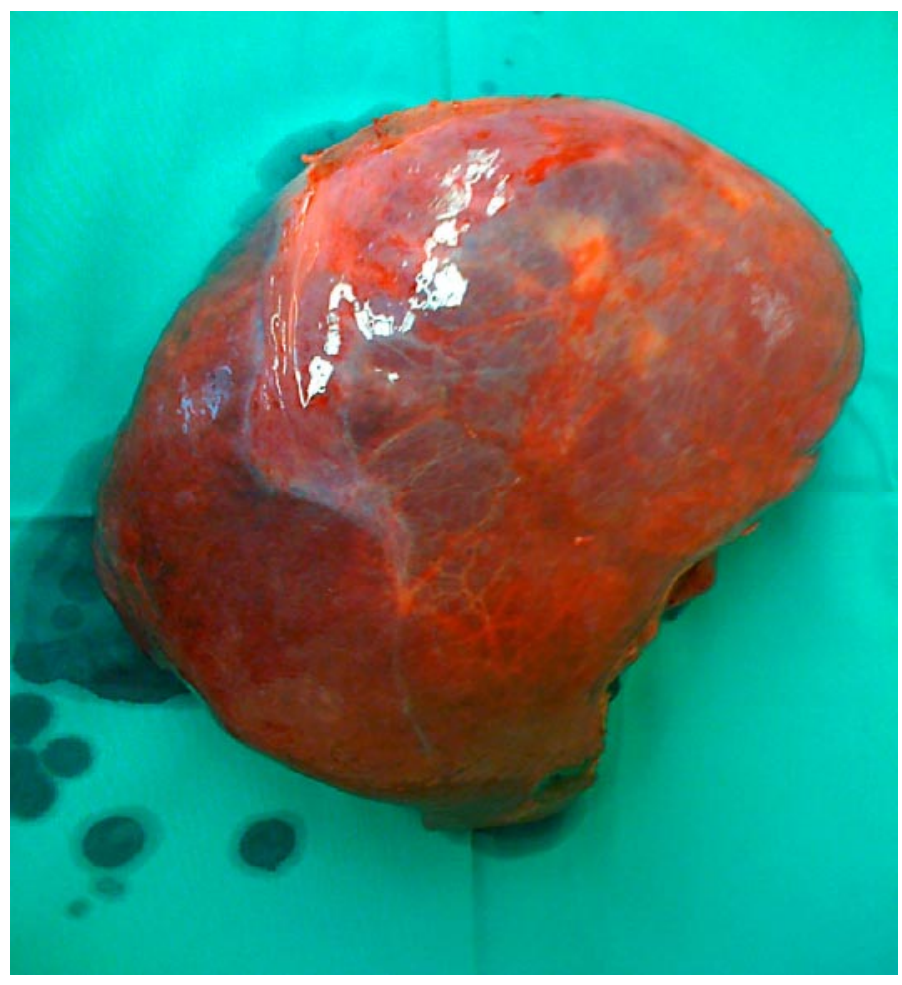

Fig. 4. Microscopic appearance of the hemangioma.

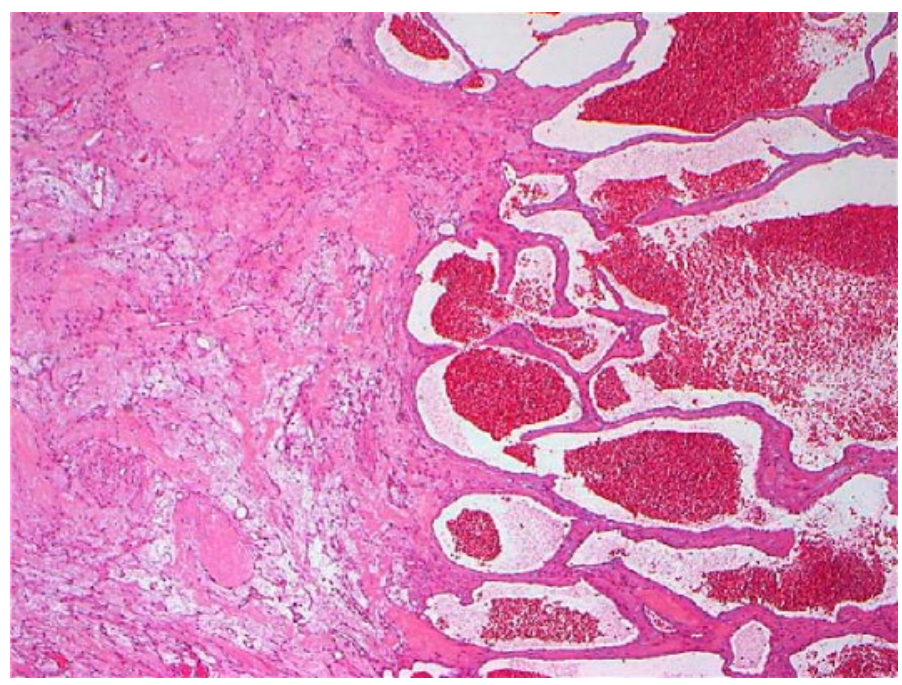




\section{References}

1 Baer HU, Dennison AR, Mouton W, Stain SC, Zimmermann A, Blumgart LH: Enucleation of giant hemangiomas of the liver. Technical and pathologic aspects of a neglected procedure. Ann Surg 1992;216:673-676.

-2 Hesselmann S, Micke O, Marquardt T, Baas S, Bramswig JH, Harms E, Willich N: Kasabach-Merritt syndrome: a review of the therapeutic options and a case report of successful treatment with radiotherapy and interferon alpha. Br J Radiol 2002;75:180-184.

-3 Brouty-Boye D, Zetter BR: Inhibition of cell motility by interferon. Science 1980;208:516-518.

-4 Lise M, Feltrin G, Da Pian PP, Miotto D, Pilati PL, Rubaltelli L, Zane D: Giant cavernous hemangiomas: diagnosis and surgical strategies. World J Surg 1992;16:516-520.

5 Reischle S, Schuller-Petrovic S: Treatment of capillary hemangiomas of early childhood with a new method of cryosurgery. J Am Acad Dermatol 2000;42:809813.

-6 Meguro M, Soejima Y, Taketomi A, Ikegami T, Yamashita Y, Harada N, Itoh S, Hirata K, Maehara Y: Living donor liver transplantation in a patient with giant hepatic hemangioma complicated by Kasabach-Merritt syndrome: report of a case. Surg Today 2008;38:463-468.

7 Longeville JH, de la Hall P, Dolan P, Holt AW, Lillie PE, Williams JA, Padbury RT: Treatment of a giant haemangioma of the liver with Kasabach-Merritt syndrome by orthotopic liver transplant: a case report. HPB Surg 1997;10:159162.

8 Frevel T, Rabe H, Uckert F, Harms E: Giant cavernous haemangioma with Kasabach-Merritt syndrome: a case report and review. Eur J Pediatr 2002;161:243-246.

$\checkmark 9$ Rodriguez V, Lee A, Witman PM, Anderson PA: Kasabach-Merritt phenomenon: case series and retrospective review of the Mayo Clinic experience. J Pediatr Hematol Oncol 2009;31:522-526.

$\checkmark 10$ Gruenberger T: Giant hemangioma of the liver presenting with abdominal compartment syndrome: a case report. Eur Surg 2005;37:57-58.

11 Hobbs KE: Hepatic hemangiomas. World J Surg 1990;14:468-471.

12 Trastek VF, van Heerden JA, Sheedy PF, Adson MA: Cavernous hemangiomas of the liver: Resect or observe? Am J Surg 1983;145:49-53.

13 Takenaka K, Gion T, Fujiwara Y, Shirabe K, Nishizaki T, Shimada M: Evaluation of indications for the surgical treatment of cavernous hemangioma of the liver. J Hepatobiliary Pancreat Surg 1996;3:98-100.

-14 Soyer P, Levesque M: Haemoperitoneum due to spontaneous rupture of hepatic hemangiomatosis: Treatment by superselective arterial embolization and partial hepatectomy. Aust Radiol 1995;39:90-92.

15 Mazziotti A, Jovine E, Grazi GL, Pierangeli F, Gozetti G: Spontaneous subcapsular rupture of hepatic haemangioma. Eur J Surg 1995;161:687-689.

16 Andersson R, Bengmark S: Surgical treatment of cavernous hemangiomas of the liver. Acta Chir Scand 1988;154:577-579.

17 Morley JE, Myers JB, Sack FS, Kalk F, Epstein EE, Lannon J: Enlargement of cavernous haemangioma associated with exogenous administration of estrogens. S Afr Med J 1974;48:695-697.

18 Takahashi T, Kuwao S, Katagiri H, Kakita A: Multiple liver hemangiomas enlargement during long-term steroid therapy for myastenia gravis. Dig Dis Sci 1998;43:1553-1561.

19 Velin P, Dupont D, Golkar A, Valla JS: Neonatal Kasabach-Merritt syndrome healed by complete surgical excision of the angioma. Arch Pediatr 1998;5:295297.

20 Alper A, Ariogul O, Emre A, Uras A, Okten A: Treatment of liver hemangiomas by enucleation. Arch Surg 1988;123:660-661.

-21 Klompmaker IJ, Sloof MJ, van der Meer J, de Jong GM, de Bruijn KM, Bams JL: Orthotopic liver transplantation in a patient with a giant cavernous hemangioma of the liver and Kasabach-Merritt syndrome. Transplantation 1989;48:149-151. 